\title{
Seasonal dynamics of photosynthesis and total carbon gain in bearing and nonbearing pistachio (Pistacia vera L.) shoots
}

\author{
G. MARINO ${ }^{* * *,+}$, M. LA MANTIA*, T. CARUSO* ${ }^{*}$ and F.P. MARRA* \\ Department of Agricultural and Forestry Science, University of Palermo, Viale delle Scienze 11, 90128 Palermo, Italy* \\ Department of Land Air and Water Resources, 213, Veihmeyer Hall, University California at Davis, One Shields Avenue, \\ 95616 Davis, CA, USA **
}

\begin{abstract}
Seasonal changes in leaf gas exchange, assimilation response to light and leaf area were monitored in bearing and nonbearing pistachio shoots. Shoot bearing status did not directly affect leaf photosynthetic rate. However, photosynthetic light-response curves strongly varied during the season demonstrating the dominant effect of the tree's seasonal phenology on assimilation. Early in the season low photosynthetic rates were associated with high rates of dark respiration indicating limited photosynthesis in the young leaves. As leaves matured, dark respiration decreased and assimilation reached maximum values. Photosynthetic efficiency was strongly reduced late in the season due to leaf age and senescence. Fruit load precipitated an early leaf senescence and drop that resulted in a 53\% decrease in leaf area in bearing $v s$. nonbearing shoots, strongly decreasing the seasonal photosynthetic performance of bearing shoots. Bearing shoots produced a $26 \%$ lower seasonal carbon gain compared to nonbearing shoots.
\end{abstract}

Additional key words: alternate bearing; bud drop; carbohydrates; light-response curve; photosynthetic photon flux density.

\section{Introduction}

In the past decade global pistachio acreage increased sharply due to demand, profitability and the drought and salinity tolerance of Pistacia spp. Commercial pistachio production is characterized by alternate bearing (Crane and Iwakiri 1981); the alternate bearing index is routinely as high as 0.5 on a $0-1$ scale. While alternate bearing has never been demonstrated to limit tree life or productivity, the sharp swings in net return are disruptive to commercial production.

Pistachio nuts are produced on a rachis borne on oneyear-old wood from buds produced on the previous year preformed shoot growth. The visible mechanism of alternate bearing in pistachios is the abscission of these fruit buds within the year they are produced. This bud abscission is correlated in time with the seasonal vegetative and reproductive cycle of pistachio. Inflorescence bud break and apical shoot growth occur simultaneously in March. In April, the flowers bloom, set fruit and the fruit pericarp first enlarges and then lignifies in late May-June. In late June, the embryo starts growing (Crane and Iwakiri 1981). The abscission of the inflorescence buds occurs simultaneously with this period of embryo growth and is more intense when the crop on one-year-old wood is heavy. During a heavy crop year, $80 \%$ of the next year's fruit buds abscise, compared to off crop years, when only $20 \%$ of the buds abscise (Takeda et al. 1980).

This temporal coincidence of bud drop and nut development suggests a competition between the developing embryo and inflorescence buds for available resources. Within a season a pistachio shoot has three potential crops (Spann et al. 2008): the current crop (the nuts that will be harvested that season), located at the proximal end of the branch, on one-year-old wood; the following year crop, e.g. the current year shoot bearing inflorescence buds; the preformed buds developing in the terminal vegetative bud.

Received 18 November 2016, accepted 8 June 2017, published as online-first 18 July 2017.

${ }^{+}$Corresponding author; e-mail: giumarino@ucdavis.edu

Abbreviations: $\mathrm{CG}_{\text {daily }}$ - daily carbon gain; DAFB - days after full bloom; $\mathrm{I}_{\mathrm{c}}$ - compensation point; $\mathrm{I}_{\mathrm{s}}$ - saturation point; LA - leaf area; $P_{\mathrm{N}}-$ net photosynthesis; $P_{\mathrm{Ndaily}}-$ total daily photosynthesis; $P_{\mathrm{Nmax}}-$ light-saturated net photosynthetic rate; $R_{\mathrm{D}}-$ respiration rate;

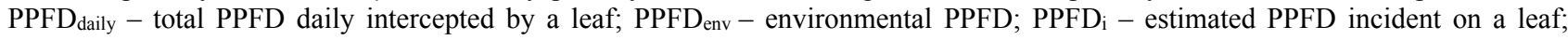
PPFD leaf - measured PPFD incident on a leaf; $\alpha$-apparent quantum yield; $\theta$ - curvature factor.

Acknowledgements: We express our gratitude to L. Ferguson for correcting the English language and for helpful and constructive suggestions and critical reading of the manuscript. We thank also the editor and reviewers for helpful comments on the manuscript. 
As Kester et al. (1996) and Johnson and Lakso (1986a,b) reported for almond and apple spurs, respectively, the pistachio shoot is a semi-autonomous unit with regard to carbohydrate availability (Watson and Casper 1984, Sprugel et al. 1991, Heerema 2005, Tombesi et al. 2011). Within this "unit" there is one main source, the distal leaves on current year growth, and one main sink, the proximal fruits, located on the one-year-old growth (Davis and Sparks 1974, Spann et al. 2008).

Large crop loads may deplete carbohydrate and/or nutrient reserves of the shoot, influencing the development of the subsequent year inflorescence buds and triggering alternate bearing. Multiple studies have investigated the carbohydrate dynamics in bearing and nonbearing pistachio branches (Crane and Al-Shalan 1977, Marra et al. 1998, 2004; Nzima et al. 1999, Vemmos 1999, Spann et al. 2008). Most reported lower carbohydrate concentrations in bearing branches (Crane and Iwakiri 1987, Nzima 1997, Marra et al. 1998) or lower bud drop in branches girdled at the base of the current year shoot (Vemmos 2005).

Others suggested endogenous plant growth regulators produced by the fruits or leaves directly inhibited or enhanced bud abscission (Chacko et al. 1972, Crane and Nelson 1972, Monselise and Goldsmith 1982, Crane and Iwakiri 1987, Pontikis 1990). However, the multiple endogenous hormones in buds and fruits neither reliably correlated with bud abscission nor prevented abscission as external applications (Crane and Nelson 1972, Takeda and Crane 1980, Vemmos et al. 1994).

Less information is available about the total quantity of carbon assimilated through a season by the pistachio shoot and how crop load affects it.

Seasonal and diurnal variation in maximum photosynthetic rate has been studied by multiple authors (Lin et al. 1984, Vemmos 1994, Novello and de Palma 1995, de Palma and Novello 1996, Gijón et al. 2011). Generally,

\section{Materials and methods}

Experimental site: The trial was conducted in 2009 on five 24-year-old uniform pistachio trees of cv. Bianca grafted onto $P$. terebinthus rootstock, spaced at $5 \times 6 \mathrm{~m}$, in a commercial orchard near Caltanissetta (Sicily, $37^{\circ} 26^{\prime} 02^{\prime}$ N, $370 \mathrm{~m}$ a. s. 1.). Trees were rain-fed and received routine commercial horticultural care. The soil was: $33.8 \%$ sand, $15.1 \%$ silt, and $51.1 \%$ clay. The climate was typical of the Mediterranean areas with five dry months (from May to September, total precipitation of $48.2 \mathrm{~mm}$ ) and average annual precipitation of $452.2 \mathrm{~mm}$ (30-year average). June and July are the driest months (4.8 and $4.2 \mathrm{~mm}$ of rain), the mean minimum air temperature ranged from $4.3^{\circ} \mathrm{C}$ in February to $18.6^{\circ} \mathrm{C}$ in August; the mean maximum air temperature ranged from $11.6^{\circ} \mathrm{C}$ in December to $30.1^{\circ} \mathrm{C}$ in August. The mean yearly temperature was $15.4^{\circ} \mathrm{C}$. photosynthetic rates are lower in nonbearing branches (Baninasab et al. 2007). The inhibitory effect of high starch concentration on the photosynthetic process (Vemmos et al. 2012) and/or a direct effect of growth regulators produced by the developing embryos on Rubisco activity (Wareing 1968) have been suggested as possible reasons.

However, this response can vary with the genotype (Sajjadinia et al. 2010) and phenological stage of a tree. Baninasab et al. (2007) found differences between the $P_{\mathrm{N}}$ rate of bearing and nonbearing trees (higher $P_{\mathrm{N}}$ in the bearing ones) only before $70 \mathrm{~d}$ after full bloom (DAFB) and similar values in the second part of the season, when the decreased nitrogen content and earlier leaf senescence in bearing branches affected the $P_{\mathrm{N}}$. However, seasonal photoassimilate production is not only a function of leaf photosynthetic rate but also of total leaf area.

The effect of fruit load on total branch leaf area is better understood. It has been demonstrated that, at the branch level, fruit load reduces total leaf area (Nzima et al. 1997; Marra et al. 1998), thus reducing the photosynthetic area of a bearing shoot (Baninasab et al. 2007). As a result, bearing branches have higher leaf assimilation rates but a lower photosynthetic area compared to nonbearing branches. The extent, to which these two factors affect the total quantity of assimilates produced within a season, has not been well integrated and is fundamental for understanding alternate bearing dynamics in Pistacia species. The objectives of the current study were to: (1) assess the effect of the bearing status on the seasonal dynamics of the photosynthetic process in pistachio leaves; (2) integrate this information with shoot leaf area and light interception to describe and quantify seasonal $\mathrm{CO}_{2}$ assimilation capacity of bearing and nonbearing pistachio shoots; (3) use this information to estimate the total carbon assimilated by bearing and nonbearing branches of pistachio trees throughout a season.

Meteorological data were acquired with a weather station installed in the experimental field. Hourly air temperature and environmental photosynthetic photon flux density $\left(\right.$ PPFD $_{\text {env }}$ ) were measured using a MP100 sensor (Rotronic Instruments Ltd., UK) and a Li-190 Quantum sensor (Li-Cor Biosciences, Nebraska, USA), respectively. The sensors were connected to a CR1000 (Campbell Scientific Inc., Utah) data logger that recorded throughout the growing season.

Leaf growth: Starting $4 \mathrm{~d}$ before full bloom (FB, 23 April) until the end of September, two bearing and two nonbearing shoots (current-year growth and one-year-old wood) per tree, located at medium height in the canopies, were collected weekly and brought to the laboratory to measure leaf area using a leaf area meter (WinFOLIA System, Regent Instrument Inc., Canada). These data were 
used to plot shoot leaf growth for the entire period. The following sigmoid function was used to fit data as proposed by Marra et al. (2009):

$$
y=\frac{a}{1+\mathrm{e}^{\left(\frac{\mathrm{x}-\mathrm{b}}{\mathrm{c}}\right)}}
$$

in which $\mathrm{y}$ is shoot leaf area, $\mathrm{x}$ is the time in days from full bloom, $a$ is the asymptote of the function, $\mathrm{b}$ represents the value (days) at which the function is $50 \%$ of its width and c defines the shape of the curve (dimensionless unit). An additional two bearing (3-5 clusters) and two nonbearing shoots (one per row side) were tagged in each of the five selected trees, and the number of leaves and leaflets were monitored over the season.

Leaf PPFD measurements: In each tree, light measurements were taken on a shoot with seven leaves (numbered from 1-7 from apex to base), selected from the outer eastern canopy. On every numbered leaf, instantaneous incident PPFD (PPFD ${ }_{\text {leaf }}$ ) was measured continuously during a week in mid-July. Silicon photosensors (silicon NPN phototransistor, model DFT02, Micropto, Italy) were placed on the adaxial surface of the apical leaflet of each leaf.

The lightweight photosensors were connected by thin wires and secured with narrow plastic bands placed across the wires. This allowed them to follow leaf movement without influencing their natural positions. The photosensors were previously calibrated with a quantum sensor (LI-190; LI-COR Inc., Lincoln, NE, USA). Data, averaged every min, were recorded using a CR1000 data logger (Campbell Scientific Inc., Utah, USA). The PPFD leaf $_{\text {data }}$ collected were then recalculated as a percentage of the corresponding PPFD $_{\text {env }}$ values measured at the same time in the meteorological station. The obtained percentages were then applied to the instantaneous PPFD $_{\text {env }}$ recorded throughout the season to estimate the seasonal trend of instantaneous PPFD values $\left(\right.$ PPFD $\left._{\mathrm{i}}\right)$ incident on each leaf. The total PPFD intercepted during each day of the season $\left(\mathrm{PPFD}_{\text {daily }}\right)$ by each leaf of the shoot was then calculated as an integral of the PPFD $_{\mathrm{i}}$.

Gas-exchange measurements: Once every two weeks, from May to September, the response curves of net photosynthesis $\left(P_{\mathrm{N}}\right)$ at variable PPFD were determined on the apical leaves of the selected shoots. Considering that one response curve required $20 \mathrm{~min}$, we decided to perform them on three of five selected trees, to keep measurements between 11:00 and 13:00 h. Measurements were taken with a CIRAS-2 portable infrared gas analyzer ( $P P$ Systems $^{\circledR}$, Hitchin, UK), connected to an automatic assimilation chamber (PLC6 automatic broad leaf cuvette). The leaf cuvette was equipped with a quartz halogen light unit providing automatic control of PPFD, and cuvette and leaf temperature sensors. During the measurements, temperature and $\mathrm{CO}_{2}$ concentration inside the cuvette were maintained at constant levels (approximately $27^{\circ} \mathrm{C}$ and $380 \mathrm{ppm}$ ), humidity was reduced by $20 \%$ with respect to air relative humidity and the air flow rate within the system was set at $200 \mathrm{ml} \mathrm{min}^{-1}$. PPFD was gradually decreased from 1,500 to $0 \mu \mathrm{mol} \mathrm{m} \mathrm{m}^{-2} \mathrm{~s}^{-1}$ at time intervals of $3 \mathrm{~min}$ to acclimatize the leaf to each irradiance level. Three measurements were taken at each light level over a 2-min period.

The nonrectangular hyperbola model proposed by Marshall and Biscoe (1980) was used to fit $P_{\mathrm{N}}-$ PPFD response curves:

$$
P_{\mathrm{N}}=\frac{\alpha \mathrm{I}+P_{\mathrm{N} \text { max }}-\sqrt{\left(\alpha \mathrm{I}+P_{\mathrm{N} \max }\right)^{2}-4 \alpha \mathrm{II} P_{\mathrm{Nmax}} \theta}}{2 \theta}-R_{\mathrm{D}}
$$

where: $P_{\mathrm{N}}-$ leaf net photosynthesis $\left[\mu \mathrm{mol} \mathrm{m} \mathrm{m}^{-2} \mathrm{~s}^{-1}\right.$; $\alpha$ - apparent quantum yield $\left[\operatorname{mol}\left(\mathrm{CO}_{2}\right) \operatorname{mol}(\text { photon })^{-1}\right]$; $P_{\text {Nmax }}-$ maximum photosynthetic capacity $\left[\mu \mathrm{mol} \mathrm{m} \mathrm{m}^{-2} \mathrm{~s}^{-1}\right.$; $\mathrm{I}$ - PPFD $\left[\mu \mathrm{mol} \mathrm{m} \mathrm{m}^{-2} \mathrm{~s}^{-1}\right.$; $\theta$ - curvature factor [dimensionless]; $R \mathrm{D}-$ dark respiration $\left[\mu \mathrm{mol} \mathrm{m} \mathrm{m}^{-2} \mathrm{~s}^{-1}\right.$ ].

The values of PPFD at the compensation point $\left(\mathrm{I}_{\mathrm{c}}\right)$ were back-calculated from the model, while the PPFD at which the onset of saturation occurred $\left(\mathrm{I}_{\mathrm{S}}\right)$ was calculated using the equation proposed by Pasian and Lieth (1989):

$$
\mathrm{I}_{\mathrm{S}}=\frac{2\left(P_{\mathrm{Nmax}}+R_{\mathrm{D}}\right)}{\propto}
$$

Carbon gain estimation: The photosynthetic response curves, measured during the growing season (Eq. 2), were used to estimate the instantaneous leaf photosynthesis for each leaf of the shoot throughout the season using the calculated PPFD $_{\mathrm{i}}$ values. For each day of the season, total daily photosynthesis $\left(P_{\text {Ndaily }}\right)$ was then calculated as the integral (from 06:00 to 20:00 h) of the instantaneous values and plotted against the daily PPFD daily of the same day. The seasonal daily carbon gain $\left(\mathrm{CG}_{\text {daily }}\left[\mathrm{mmol} \mathrm{d}^{-1}\right]\right)$ for an average bearing and nonbearing shoot was estimated, for each day of the season, as follows:

$$
\mathrm{CG}_{\text {daily }}=P_{\mathrm{N}_{\text {daily }}} \times \mathrm{LA}
$$

where $P_{\text {Ndaily }}$ represents the shoot average daily assimilation per unit of leaf area $\left[\mathrm{mmol} \mathrm{m}^{-2} \mathrm{~s}^{-1}\right]$ and LA $\left[\mathrm{m}^{2}\right]$ the average leaf area per shoot for the corresponding day (Eq. 2).

Statistical analysis: Parameters for each regression were estimated using TableCurve $2 D$ software (SYSTAT Software Inc., Chicago, IL). Statistical analysis (ANOVA) was carried out using Systat package (SYSTAT Software 12 Inc., Chicago, IL). Statistical significance was set at $p \leq 0.05$. 


\section{Results}

The mean air temperature (daily) and mean PPFD $_{\text {env }}$ (from 06:00 to 20:00 h) measured in the experimental field showed seasonal trends typical of the Mediterranean climate (Fig. 1). The mean temperature increased from $15^{\circ} \mathrm{C}$ to a maximum of $30^{\circ} \mathrm{C}$ in the beginning of July and through the first week of August. Subsequently, the mean temperature decreased again to reach $15^{\circ} \mathrm{C}$ at the end of the season. The mean PPFD $_{\text {env }}$ reached 1,600-1,700 $\mu \mathrm{mol}$ $\mathrm{m}^{-2} \mathrm{~s}^{-1}$ from the beginning of the season until the end of July, with more overcast days before the second week of June. By the second week of July, mean values of PPFD ${ }_{\text {env }}$ decreased slightly.

The PPFD intercepted by the single leaves (PPFD leaf $_{\text {) }}$ varied greatly depending on the leaf position on the shoot (Fig. 2). Light interception was higher in the apical leaves (numbers 1 and 2), which, while attenuated by approximately $40 \%$, had the same bell-shaped trend as the reference sensor. In the mid-shoot, leaves 3 and 4, the light interception had two peaks. The first peak was at 11:00 h, when leaves intercepted nearly $100 \%$ of the PPFD $D_{\text {env. The }}$ second was at 15:00 h, when leaves intercepted $50 \%$ of the PPFD $_{\text {env. The lowest }}$ PPFD $D_{\text {leaf }}$, approximately $20 \%$ of PPFD $_{\text {env }}$, intercepted by leaves 5, 6, and 7, indicated the deepest shading at midday on leaves at the base of the shoot.

As bearing and nonbearing shoots exhibited similar responses to light (Fig. 3A) and equation parameters (Eq. 2) were not significantly different (data not shown), the photosynthesis data of both treatments was plotted together in subsequent analyses.

However, the response of $P_{\mathrm{N}}$ to PPFD varied strongly during the season (Fig. 3B). For this reason, response curves were pooled together in three different groups based on similar parameters (Table 1) and the growth stages described by Goldhamer (2005): stage I or rapid pericarp growth, from the beginning of the season until the 27 May (32 DAFB); stage II or endocarp hardening, from the end of May until the 20 July (32-85 DAFB); stage III or embryo development and fruit ripening lasting until the end of the season (138 DAFB). From stage I to stage II, a strong increase in $P_{\text {Nmax }}$ (from 15 to $19 \mu \mathrm{mol} \mathrm{m}^{-2} \mathrm{~s}^{-1}$ ) and $\theta$ (from 0.69 to 0.89 ) was observed, while $\mathrm{I}_{\mathrm{s}}$ had a similar value (about $1,300 \mu \mathrm{mol} \mathrm{m} \mathrm{m}^{-2} \mathrm{~s}^{-1}$ ) and $R_{\mathrm{D}}$ and $\mathrm{I}_{\mathrm{c}}$ significantly decreased (from 2.96 to $1.45 \mu \mathrm{mol} \mathrm{m}^{-2} \mathrm{~s}^{-1}$ and from 114 to $44 \mu \mathrm{mol} \mathrm{m} \mathrm{m}^{-2} \mathrm{~s}^{-1}$, respectively); no significant differences in the apparent quantum yield $(\alpha)$ were observed (Table 1). However, from stage II to stage III there was a substantial reduction in all the curve parameters.

Net photosynthesis of individual leaves, integrated over the day $\left(P_{\text {Ndaily }}\right)$, was nonlinearly related to the PPFD $_{\text {daily }}$ in all the growth stages (Fig. 4). The slope of these relationships was significantly higher at the stage II than in the other two stages.

On a shoot, maximum leaf area was significantly higher on nonbearing shoots $\left(1,094 \mathrm{~cm}^{2}\right)$ compared to bearing shoots $\left(839 \mathrm{~cm}^{2}\right)$ (Fig. 5). Both treatments achieved 50\% leaf expansion at about 13 DAFB (parameters b of the Eq. 1).

At full leaf expansion, there was no significant difference in number of leaves per shoot between bearing and nonbearing shoots (Table 2). However, there were slightly more leaflets on nonbearing compared to bearing shoots.

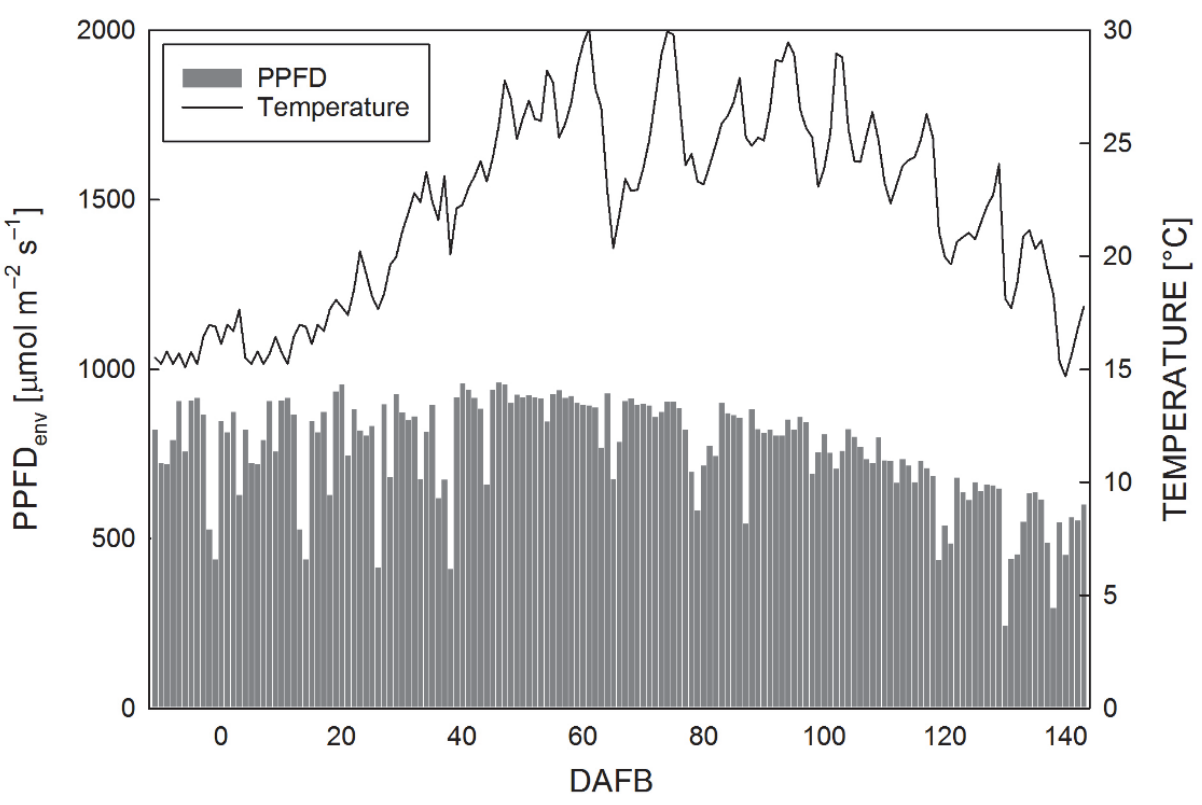

Fig. 1. Seasonal trend of daily (from 06:00 to 20:00 h) mean of environmental PPFD (PPFDenv) and daily mean temperature recorded in the meteorological station located inside the experimental field. 


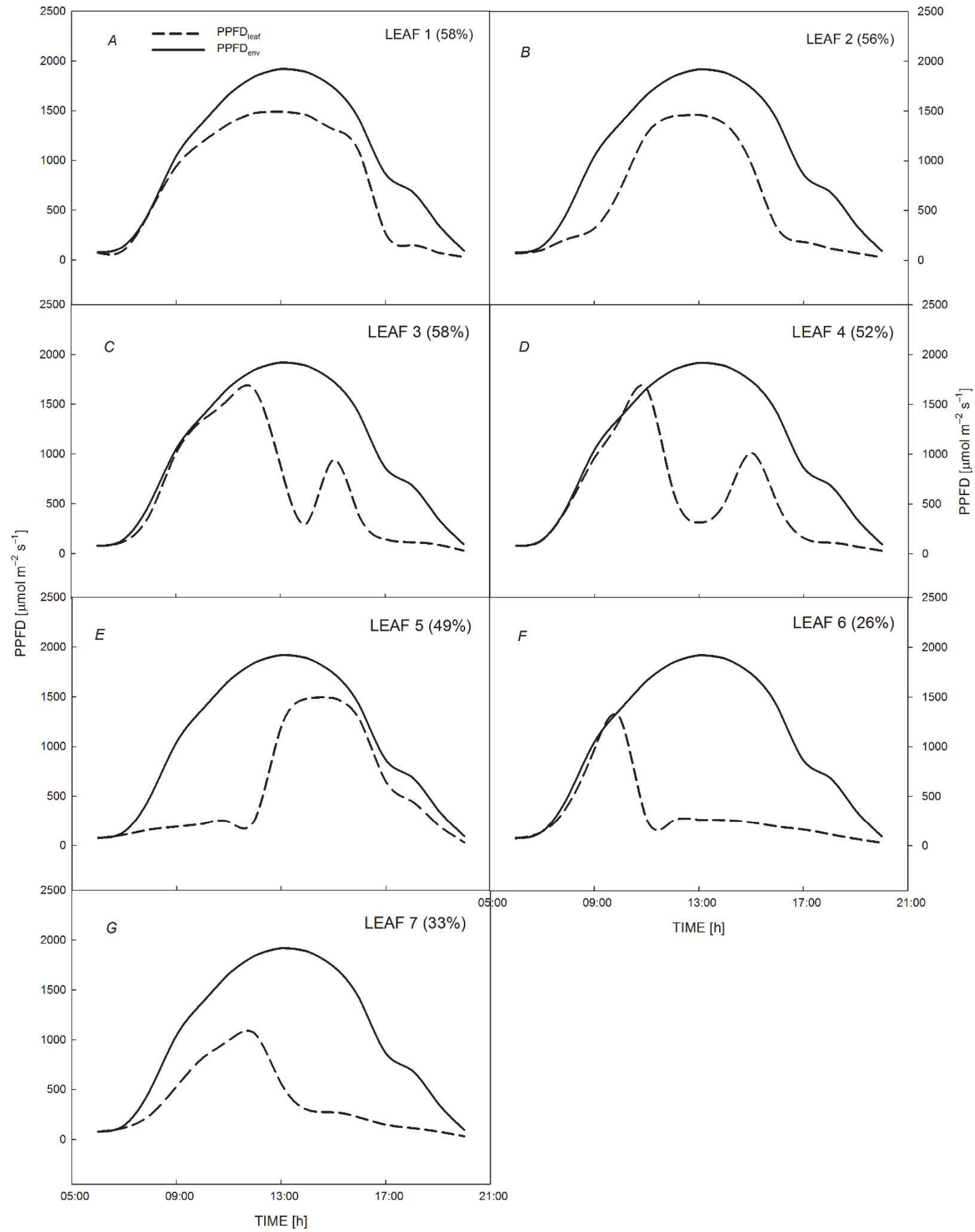

Fig. 2. Daily trends (from 6:00 to 20:00 h) of measured PPFD incident on each leaf (PPFDleaf, dotted line) as a proportion of the environmental PPFD (PPFD ${ }_{\text {env }}$, solid line) during a typical clear-sky day of July. The percentage values in the graphs represent the proportion of total light intercepted during the whole day by the leaf with respect to total incident light outside the canopy calculated as integrals of the curves in the graphs. Leaves are numbered from apex (leaf $1, A)$ to base (leaf $7, G)$. 


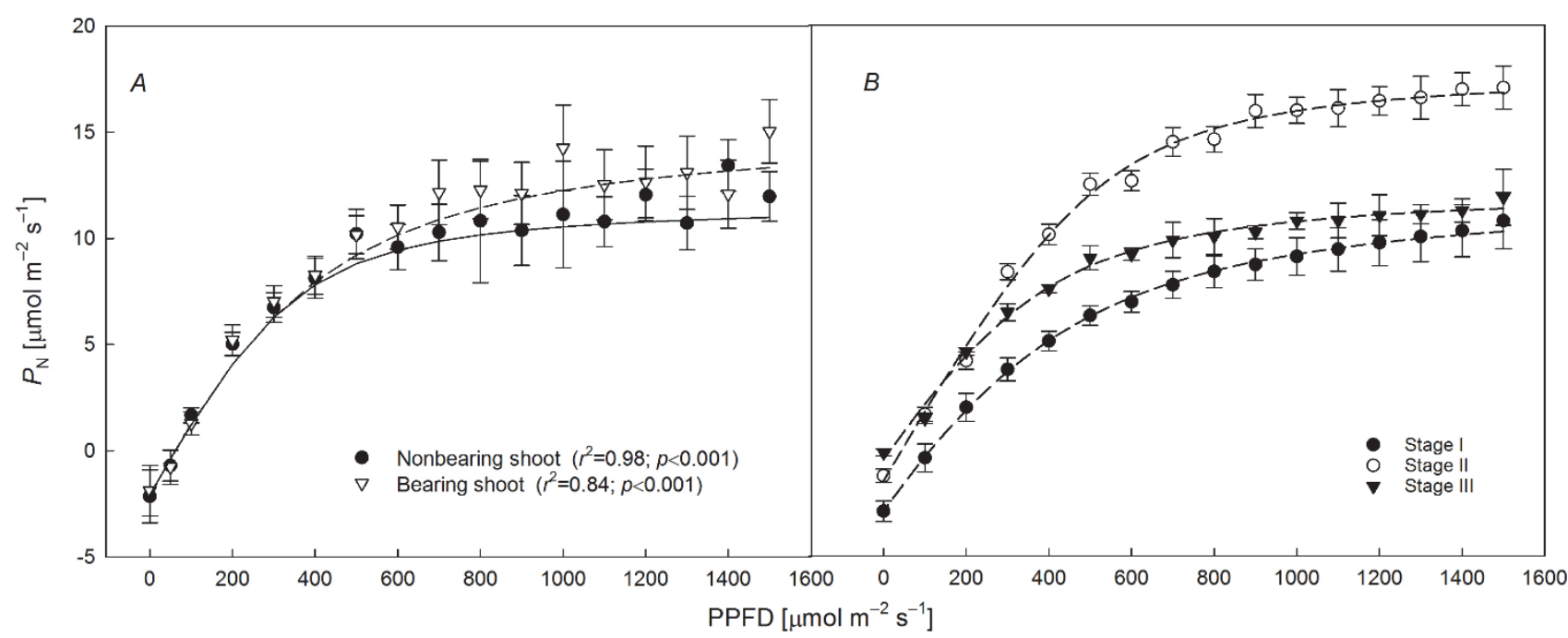

Fig. 3. Response curve of net photosynthesis $\left(P_{\mathrm{N}}\right)$ to PPFD levels fitted for $(A)$ bearing and nonbearing shoots and for $(B)$ each growth stage of pistachio (Goldhamer 2005) using the equation 2. The regression had significant $r^{2}=0.99$ and $p \leq 0.001$. Each point is the average of all the measurements made on all the trees in each growth stage. Error bars indicate standard errors of means.

Table 1. Maximum net photosynthetic rate $\left(P_{\mathrm{Nmax}}\right)$, apparent quantum yield $(\alpha)$, dark respiration $\left(R_{\mathrm{D}}\right)$, convexity parameter $(\theta)$, compensation point $\left(\mathrm{I}_{\mathrm{c}}\right)$ and saturation point $\left(\mathrm{I}_{\mathrm{S}}\right)$ obtained from the $P_{\mathrm{N}}$ response curve to PPFD of all trees at the different growth stages (Goldhamer 2005) using Eqs. 2 and 3. Values are given as means \pm SE for all the measurements made for both bearing and nonbearing shoot in each growth stage.

\begin{tabular}{lllllrr}
\hline Growth stage & $P_{\text {Nmax }}\left[\mu \mathrm{mol} \mathrm{m} \mathrm{m}^{-2} \mathrm{~s}^{-1}\right]$ & $\alpha\left[\mu \mathrm{mol} \mathrm{m} \mathrm{s}^{-1}\right]$ & $R_{\mathrm{D}}\left[\mu \mathrm{mol} \mathrm{m} \mathrm{m}^{-2} \mathrm{~s}^{-1}\right]$ & $\theta$ & $I_{\mathrm{c}}\left[\mu \mathrm{mol} \mathrm{m}^{-2} \mathrm{~s}^{-1}\right]$ & $I_{\mathrm{s}}\left[\mu \mathrm{mol} \mathrm{m}^{-2} \mathrm{~s}^{-1}\right]$ \\
\hline I & $15.09 \pm 0.25$ & $0.027 \pm 0.001$ & $2.86 \pm 0.16$ & $0.69 \pm 0.04$ & 114 & 1,329 \\
II & $19.39 \pm 0.94$ & $0.033 \pm 0.003$ & $1.45 \pm 0.46$ & $0.89 \pm 0.05$ & 44 & 1,263 \\
III & $12.78 \pm 0.64$ & $0.027 \pm 0.003$ & $0.44 \pm 0.31$ & $0.79 \pm 0.09$ & 16 & 979 \\
\hline
\end{tabular}

Table 2. Number of leaves, number of leaflets and total leaf area per shoot, in bearing and nonbearing trees at full leaf expansion (40 DAFB) and at harvest after summer leaf drop (138 DAFB). Also shown are the number of rachii per shoot (R/B) and average number of fruits per rachis $(\mathrm{F} / \mathrm{R})$ at harvest. Values are given as means $\pm \mathrm{SE}(n=5)$.

\begin{tabular}{|c|c|c|c|c|c|c|c|c|}
\hline & \multicolumn{3}{|c|}{ Fully expanded leaf } & \multicolumn{5}{|l|}{ Harvest } \\
\hline & Leaves [n] & Leaflets [n] & Leaf area $\left[\mathrm{cm}^{2}\right]$ & Leaves [n] & Leaflets [n] & Leaf area $\left[\mathrm{cm}^{2}\right]$ & $\mathrm{R} / \mathrm{B}[\mathrm{n}]$ & $\mathrm{F} / \mathrm{R}[\mathrm{n}]$ \\
\hline Bearir & $6.1 \pm 0.8$ & $24.3 \pm 0.9$ & $838.8 \pm 22.2$ & $3.7 \pm 0.2$ & $13.9 \pm$ & $508.8 \pm 19.9$ & $4.0 \pm 0.1$ & $9.6 \pm 0.3$ \\
\hline Nonbearing & $6.7 \pm 0.1$ & $28.9 \pm 0.8$ & $1094.1 \pm 26.5$ & $6.5 \pm 0.1$ & $27.6 \pm 0.8$ & $1061.5 \pm 60$ & - & - \\
\hline
\end{tabular}

Starting at $110 \mathrm{DAFB}$, an intense and premature leaf and leaflet drop was observed in bearing shoots (Fig. 5, Table 2). This leaf drop reduced the number of leaves and leaflets in the bearing shoots by $40 \%$ by the end of the season contrary to a $5 \%$ reduction observed in nonbearing shoots. This resulted in a $53 \%$ higher total leaf area per shoot in nonbearing compared to bearing trees (Table 2). At fruit maturity, the bearing shoots had an average of four rachii per shoot with ten fruits each.

Fig. 6 shows the daily carbon gain $\left(\mathrm{CG}_{\text {daily }}\right)$ during the

\section{Discussion}

These results confirmed the dominant role of tree phenological stage interacting with tree bearing status in season calculated on a shoot basis. $\mathrm{CG}_{\text {daily }}$ increased from $0 \mathrm{mmol} \mathrm{d}^{-1}$ (stage I) to a maximum of $5 \mathrm{mmol} \mathrm{d}^{-1}$ during the stage II in nonbearing shoots. In stage III, $\mathrm{CG}_{\text {daily }}$ had the lowest values, gradually decreasing from $30 \mathrm{mmol} \mathrm{d}^{-1}$ at $100 \mathrm{DAFB}$ to $12 \mathrm{mmol} \mathrm{d}^{-1}$ at the end of the season in the bearing shoots. The final integration of the $\mathrm{CG}_{\text {daily }}$ demonstrated the seasonal carbon gain $\left(\mathrm{CG}_{\text {seas }}\right)$ for a shoot was estimated as $3.30 \mathrm{~mol}(\mathrm{C})$ in bearing shoots and $4.45 \mathrm{~mol}(\mathrm{C})$ in nonbearing shoots.

regulating the total carbon assimilation in pistachio (Vemmos 1994, Baninasab et al. 2007, Sajjadinia et al. 
2010). Specifically, $P_{\text {Nmax }}$ showed a strong seasonal pattern with the highest values during the stage II. The same pattern has been reported by various authors as a function of leaf age ( $\mathrm{Li}$ et al. 1984, Vemmos 1994, Sajjadinia et al. 2010, Gijon et al. 2011). The higher $R_{\mathrm{D}}$ values measured during the stage I (Table 1), suggested that early in the season leaves were still expanding.
Marra's (2009) earlier report demonstrated that the higher respiration rates of both leaves and fruits were associated with the higher growth rates of both and also to the metabolism associated with new leaf tissue (Amthor 1989). Further, the lower $P_{\mathrm{Nmax}}$ values observed at this stage appeared to be related to the emergence of new leaves. Expanding leaves have been demonstrated to have

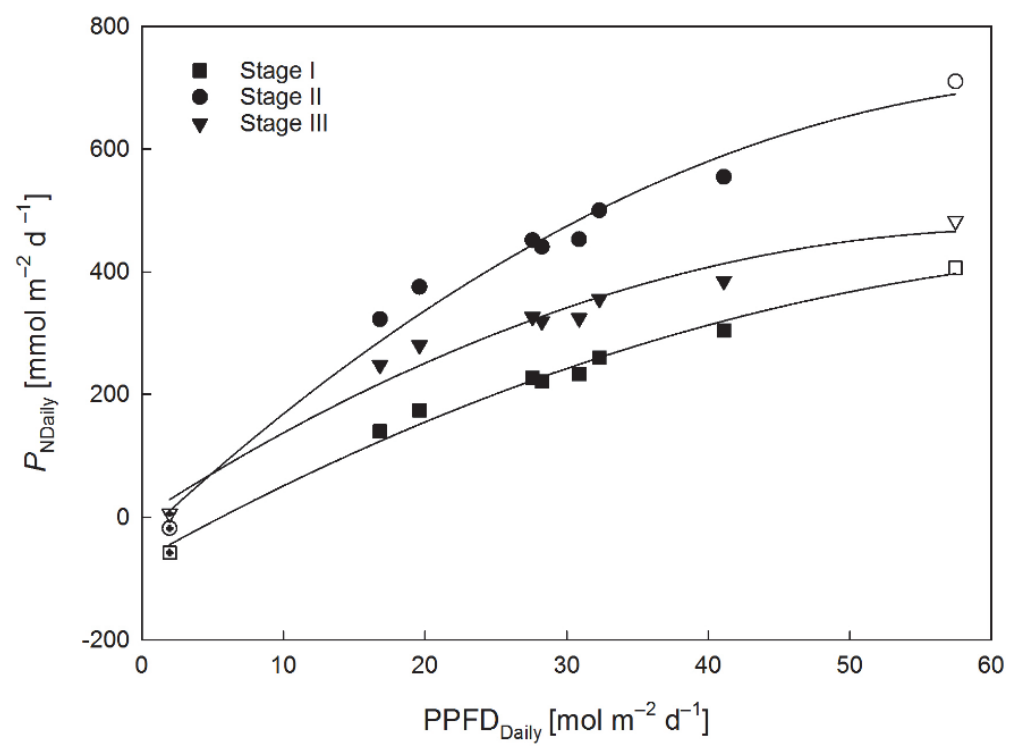

Fig. 4. Relationship between total daily photosynthesis $\left(P_{\text {NDaily }}\right)$ and total PPFD daily intercepted by a leaf (PPFD Daily) in the different growth stages (Goldhamer 2005). Each point represents an individual leaf on a shoot (filled symbols), the highest point represents a hypothetical fully sun exposed leaf (empty symbols) and the lowest point represent a hypothetical fullyshaded leaf (empty with internal dot symbols). For stage I, $P_{\text {NDaily }}=$ $-69.5+12.9$ PPFDDaily $=-0.083$ PPFDDaily ${ }^{2}$; $r^{2}=0.99 ; p<0.001$. For stage II, $P_{\text {NDaily }}=-31.3$ +21.6 PPFD Daily $=-0.16$; PPFD $_{\text {Daily }}{ }^{2} ; r^{2}=0.98$; $p<0.001$. For stage III, $P_{\text {NDaily }}=-0.16+14.9$ PPFD Daily $=-0.12$ PPFD Daily $^{2} ; r^{2}=0.97$; $p<0.001$.

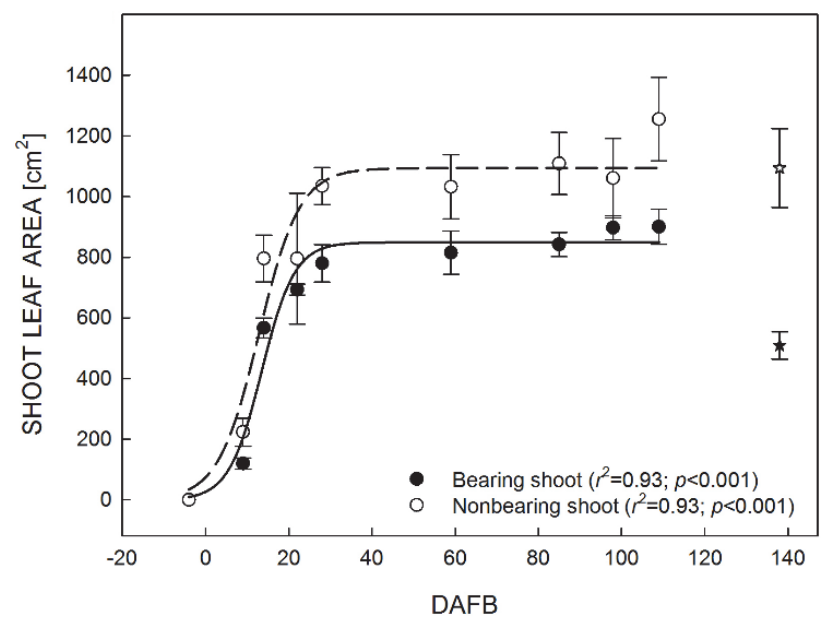

Fig. 5. Average time course of leaf area of a bearing and a nonbearing shoot. Regression parameters, obtained using the Eq. 1 for the bearing trees were: $\mathrm{a}=849.3( \pm 43.3) ; \mathrm{b}=13.5$ $( \pm 0.9) ; c=3.9( \pm 1.5)$. Regression parameters, obtained using the Eq. 1 for the nonbearing trees were: $\mathrm{a}=1094( \pm 52.5) ; \mathrm{b}=$ $12.8( \pm 1.7) ; c=4.9( \pm 1.8)$. The star points were not included in the regression and represent the leaf area at harvest. Each point is the average of ten shoots. Vertical lines represent the standard error of the means.

a reduced chlorophyll content (Kursar and Coley 1992, Woodall et al. 1998, Hieke et al. 2002), greater diurnal photoinhibition relative to mature leaves (Cai et al. 2005), and delayed stomata development; all factors that directly reduce $P$ Nmax (Schaffer et al. 1991, Cai et al. 2005).

During the stage II, when the leaves completed their development, $R_{\mathrm{D}}$ values decreased from 2.86 to $1.4 \mu \mathrm{mol}$ $\mathrm{m}^{-2} \mathrm{~s}^{-1}$ and reached the maximum photosynthetic effi-

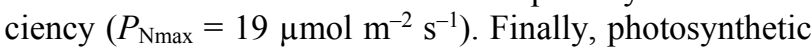
efficiency strongly decreased at the stage III as leaves aged and were possibly water stressed in this rain-fed orchard (Goldhamer et al. 2005, Gijon et al. 2010). At this stage, the rapidly developing kernels are depleting the stems carbohydrate reserves (Spann et al. 2008). Spann et al. (2008) suggested that this mid-season mobilization of stored carbohydrates directly precipitates inflorescence bud abscission. Under our trial conditions, the apical leaves intercepted a higher amount of light during the season compared to the basal leaves, resulting in higher carbohydrate production in the shoot apex. This proximity to a stronger carbohydrate source may be secondarily involved in the higher bud retention generally observed in the shoot apex. In the basal part of the shoot, where carbohydrate production is lower and the buds are closer to the major sink, the rachiis (Crane and Nelson 1971, Porlingis 1974, Crane and Iwakiri 1981), bud drop is generally higher.

Other authors correlated kernel growth with decreasing leaf nitrogen and leaf senescence (Weinbaun and Muroka 1986, Picchioni et al. 1997). Leaf $\mathrm{N}$ resorption during kernel growth is a well-documented phenomena in pistachio and supported by the high kernel protein content $(25 \%)$ of this species (Ferguson and Kader 1995). This 


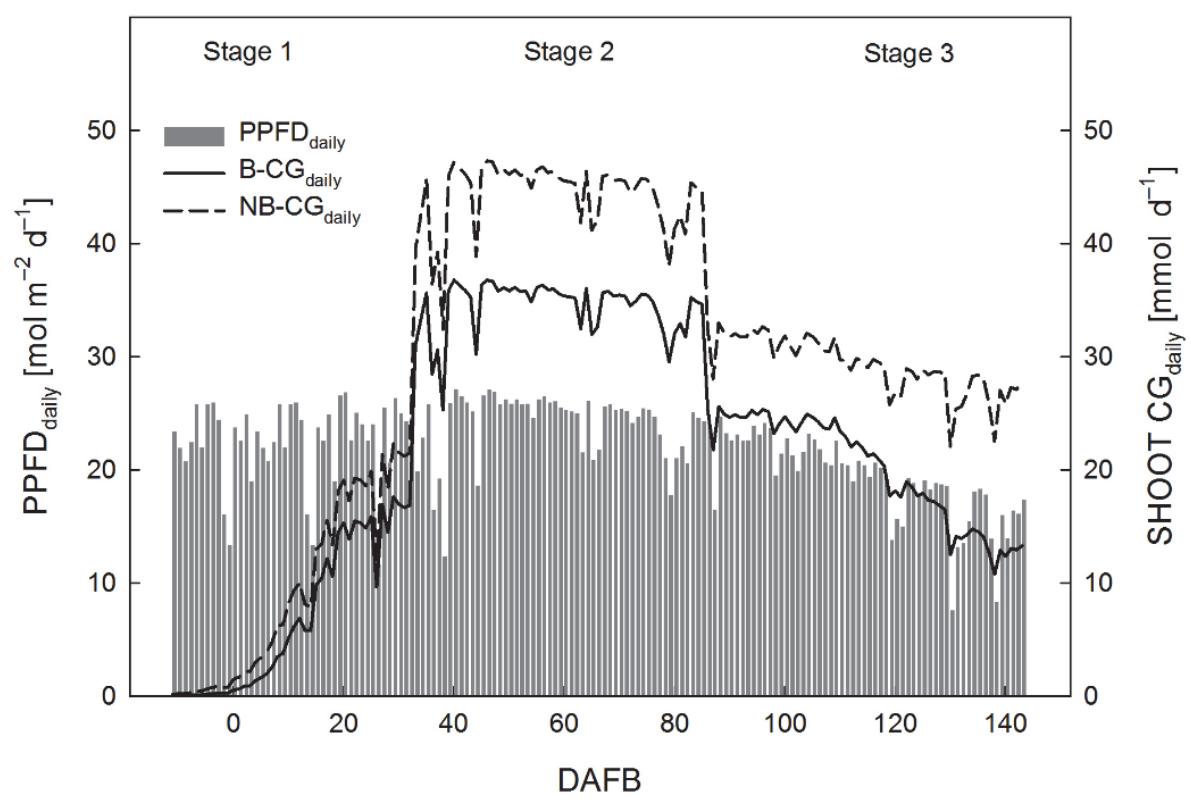

Fig. 6. Seasonal time course of the total PPFD daily intercepted by a leaf (PPFD daily) and the corresponding daily total net carbon gain $\left(\mathrm{CG}_{\text {daily }}\right)$ of a bearing and nonbearing shoot. $\mathrm{CG}_{\text {daily }}$ was calculated using the three equations reported in Fig. 4 for the three different growth stages.

strong $\mathrm{N}$ demand by the developing kernels, enhanced the decline in leaf $\mathrm{N}$ content, thus leaf senescence (Sparks 1977, Weinbaum 1988, Niederholzer et al. 1991, Weinbaum et al. 1994, Picchioni et al. 1997). This hypothesis was confirmed by the earlier leaf senescence and drop we observed in bearing $v s$. nonbearing branches (Table 2). The above reported seasonality in photosynthetic efficiency is reflected in the relationship between $P_{\mathrm{N}}$ and PPFD on a daily basis (Fig. 6).

In this experiment, no differences in the rate of $P_{\mathrm{N}}$ (per unit of leaf area) were observed between bearing and nonbearing branches, contrary to the observations in other species (DeJong 1986, Giuliani et al. 1997, Palmer et al. 1997). The differences observed in seasonal photosynthetic performance between bearing and nonbearing shoots were due to a difference in the leaf area assimilating $\mathrm{CO}_{2}$.

Leaf area is a function of leaf age, shoot bearing status and abiotic stresses. In this experiment, a significant difference was observed in the leaf area between bearing and nonbearing shoots (Table 2, Fig. 5). These results agree with those of Nzima et al. (1997) and Marra et al. (1998) suggesting leaf area was higher in nonbearing branches. By the end of the growing season, the lower leaf area and stronger leaf drop of the bearing shoots resulted in $60 \%$ lesser photosynthetic surface than that of

\section{References}

Amthor J.S.: Respiration and Crop Productivity. Pp. 54-57. SpringerVerlag, New York 1989.

Baninasab B., Rahemi M., Shariatmadari H.: Seasonal changes in mineral content of different organs in the alternate bearing of pistachio trees. - Commun. Soil Sci. Plan. 38: 241-258, 2007 nonbearing shoots. This decreased leaf area of bearing shoots was the principal factor that limited the seasonal photosynthetic performance of the bearing shoots resulting in the $26 \%$ less $\mathrm{C}$ assimilated during the season by bearing compared to nonbearing shoots. The amount of carbon lost by respiration during the growing season by the nuts [0.131 mol(C)] and leaves $[0.117 \mathrm{~mol}(\mathrm{C})]$ was previously reported by Marra et al. (2009).

Using these data for bearing branches (four rachii and six leaves), we calculated that a bearing shoot used $\sim 1.238$ $\operatorname{mol}(\mathrm{C})$ for respiration, corresponding to the $38 \%$ carbon gain through photosynthesis. These results demonstrated that the smaller leaf area and higher leaf senescence and drop, the latter due to nutrient resorption from the fruits, are the main factors that reduced the photosynthetic performance in bearing compared to nonbearing shoots.

The parameters of leaf photosynthetic light-response curves were also measured in the field, providing a physiological explanation for the seasonal variation of photosynthesis previously reported by others (Li et al. 1984 , Vemmos 1994, Sajjadinia et al. 2010, Gijon et al. 2011). The results reported here better characterize the photosynthetic behavior of Pistacia species and could be a tool for developing a carbon budget model for pistachio and understanding the alternate bearing mechanism of Pistacia.

Cai Z.Q., Slot M., Fan Z.X.: Leaf development and photosynthetic properties of three tropical tree species with delayed greening. - Photosynthetica 43: 91-98, 2005.

Chacko E.K., Singh N., Kachru R.B: Studies on the physiology of flowering and fruit growth in Mangiferae indica L. IV: 
Hormonal control of fruit development and its possible significance to biennal bearing. - Acta Hortic. 24: 155-163, 1972.

Crane J.C., Nelson M.M.: The unusual mechanism of alternate bearing in the Pistachio. - HortScience 6: 489-490, 1971.

Crane J.C., Nelson M.M.: Effects of crop load, girdling and auxin application on alternate bearing of the pistachio. - J. Am. Soc. Hortic. Sci. 97: 337-339, 1972.

Crane J.C., Iwakiri B.T.: Morphology and reproduction in pistachio. - Hortic. Rev. 3: 376-393, 1981.

Crane J.C., Iwakiri B.T.: Reconsideration of the cause of inflorescence bud abscission in pistachio. - HortScience 22: 1315-1316, 1987.

Crane J.C., Al-Shalan I.: Carbohydrate and nitrogen levels in pistachio branches as related to shoot extension and yield. - J. Am. Soc. Hortic. Sci. 102: 396-399, 1997.

Davis J.T., Sparks D.: Assimilation and translocation patterns of carbon 14 in the shoot of fruiting pecan trees Carya illinoensis. - J. Am. Soc. Hortic. Sci. 99: 468-480, 1974.

De Palma L., Novello V.: [Traits of photosynthetic activity of almond and pistachio.] - Frutticoltura 58: 55-56, 1996. [In Italian]

DeJong T.M.: Fruit effects on photosynthesis in Prunus persica. - Physiol. Plantarum 66: 149-153, 1986.

Ferguson L., Kader A.: Harvesting, transporting, processing and grading. - In: Ferguson L. (ed.): Pistachio Production Pp. 110114. Center for Fruit and Nut Crop Research and Information, University of California, Davis 1995.

Gijón M.C., Gimenez C., Perez-López D. et al.: Rootstock influences the response of pistachio (Pistacia vera L. cv. Kerman) to water stress and rehydration. - Sci. Hortic.Amsterdam 125: 666-671, 2010.

Gijón M.C., Gimenez C., Perez-López D. et al.: Water relations of pistachio (Pistacia vera L.) as affected by phenological stages and water regimes. - Sci. Hortic.-Amsterdam 128: 415422, 2011.

Giuliani R., Nerozzi F., Magnanini E., Corelli-Grappadelli L.: Influence of environmental and plant factors on canopy photosynthesis and transpiration of apple trees. - Tree Physiol. 17: 637-645, 1997.

Goldhamer D.A.: Tree water requirements and regulated deficit irrigation. - In: Ferguson L. (ed): Pistachio Production Manual, vol. 4. Pp. 103-116. Fruit and Nut Research and Information Center, University of California, Davis 2005.

Goldhamer D.A., Beede R.H., Michailides T.J. et al.: Effects of regulated deficit irrigation on shell splitting and nut quality at harvest (second year report). - In: California Pistachio Commission (ed): Annual Report. Crop Year 2004-2005. Pp. 104-106. California Pistachio Industry, Fresno 2005.

Heerema R.J.: Compartmentalization of carbon and nitrogen stresses within Almond (Prunus dulcis (Mill.) D.A.Webb) spurs. - Ph.D dissertation, University of California, Davis 2005.

Hieke S., Menzel C.M., Lüdders P.: Effect of leaf, shoot and fruit development on photosynthesis of lychee trees (Litchi chinensis). - Tree Physiol. 22: 955-961, 2002.

Johnson R.S., Lakso A.N.: Carbon balance model of a growing apple shoot: I. Development of the model. - J. Am. Soc. Hortic. Sci. 111: 160-164, 1986a.

Johnson R.S., Lakso A.N.: Carbon balance model of a growing apple shoot: II. Simulated effects of light and temperature on long and short shoots. - J. Am. Soc. Hortic. Sci. 111: 164-169, 1986b.
Kester D.E., Martin G.C., Labavitch J.M.: Growth and development. - In: Micke W.C. (ed.): Almond Production Manual. Pp. 90-97. University of California, Davis 1996.

Kursar T.A., Coley P.D.: Delayed development of the photosynthetic apparatus in tropical rain forest species. - Funct. Ecol. 6: 411-422, 1992.

Li W.K.W., Smith J.C., Platt T.: Temperature response of photosynthetic capacity and carboxylase activity in Arctic marine phytoplankton. - Mar. Ecol. Prog. Ser. 17: 237-243, 1984.

Lin T.S., Crane J.C., Ryugo K. et al.: Comparative study of leaf morphology, photosynthesis, and leaf conductance in selected Pistacia species. - J. Am. Soc. Hortic. Sci. 109: 325-330, 1984.

Marra F.P., Barone E., La Mantia M., Caruso T.: Toward the definition of a carbon budget model: seasonal variation and temperature effect on respiration rate of vegetative and reproductive organs of pistachio trees (Pistacia vera). - Tree Physiol. 29: 1095-1103, 2009.

Marra F.P., Barone E., Caruso T. et al.: Dry matter accumulation and carbohydrate content within branches of fruiting and deblossomed pistachio (Pistacia vera L.) trees. - Acta Hortic. 470: 331-339, 1998.

Marra F.P., Li Vigni L., Barone E., et al.: Histological studies on pistachio vegetative organs as related to fructification. - Acta Hortic. 636: 381-386, 2004

Marshall B., Biscoe P.V.: A model for C3 leaves describing the dependence of net photosynthesis on irradiance. - J. Exp. Bot. 31: 29-39, 1980.

Monselise S.P., Goldschmidt E.E.: Alternate bearing in fruit trees. - Hortic. Rev. 4: 128-173, 1982.

Niederholzer F.J.A., Carlson R.M., Uriu K. et al.: Seasonal partitioning of leaf and fruit potassium and fruit dry matter in French prune trees at various potassium levels. - J. Am. Soc. Hortic. Sci. 116: 981-986, 1991.

Novello V., de Palma L.: Observations on the pistachio photosynthetic activity in Southern Italy. - Acta Hortic. 419 97-102, 1995.

Nzima M.D., Martin G.C., Nishijima C.: Seasonal changes in total nonstructural carbohydrates within branches and roots of naturally "off" and "on" 'kerman' pistachio trees. - J. Am. Soc. Hortic. Sci. 122: 856-862, 1997.

Nzima M.D., Martin G.C., Nishijima C.: Effect of fall defoliation and spring shading on shoot carbohydrate and growth parameters among individual branches of alternate bearing Kerman' pistachio trees. - J. Am. Soc. Hortic. Sci. 124: 52-60, 1999.

Palmer J.W., Giuliani R., Adams H.M.: Effect of crop load on fruiting and leaf photosynthesis of 'Braeburn'/M. 26 apple trees. - Tree Physiol. 17: 741-746, 1997.

Pasian C.C., Lieth J.H.: Analysis of the response of net photosynthesis of rose leaves of varying ages to photosynthetically active radiation and temperature. - J. Am. Soc. Hortic. Sci. 114: 581-586, 1989.

Picchioni G.A., Brown P.H., Weinbaum S.A., Muraoka T.T.: Macronutrient allocation to leaves and fruit of mature, alternate-bearing pistachio trees: Magnitude and seasonal patterns at the whole-canopy level. - J. Am. Soc. Hortic. Sci. 122: 267-274, 1997.

Pontikis C.A: Effects of 2-naphthaleneacetic acid on alternate bearing of pistachio. - Fruits 45: 281-285, 1990.

Sajjadinia A., Ershadi A., Hokmabadi H. et al.: Gas exchange activities and relative water content at different fruit growth and developmental stages of ON and OFF cultivated pistachio trees. - Aust. J. Agr. Eng. 1: 1, 2010.

Schaffer B., Whiley A.W., Kohli R.R.: Effects of leaf age on gas 
exchange characteristics of avocado (Persea americana Mill.). - Sci. Hortic.-Amsterdam 48: 21-28, 1991.

Spann T.M., Beede R.H., DeJong T.M.: Seasonal carbohydrate storage and mobilization in bearing and non-bearing pistachio (Pistacia vera) trees. - Tree Physiol. 28: 207-213, 2008.

Sparks D.: Effects of fruiting on scorch, premature defoliation, and nutrient status of 'Chickasaw' pecan leaves. - J. Am. Soc. Hortic. Sci. 102: 669-673, 1977.

Sprugel D.G., Hinkley T.M. Schaap. W.: The theory and practice of branch autonomy. - Annu. Rev. Ecol. Syst. 22: 309-334, 1991.

Takeda F., Crane J.C.: Abscisic-acid in pistachio as related to inflorescence bud abscission. - J. Am. Soc. Hortic. Sci. 105: 573-576, 1980.

Takeda F., Ryugo K., Crane J.C.: Translocation and distribution of ${ }^{14} \mathrm{C}$-photosynthates in bearing and nonbearing pistachio branches. - J. Am. Soc. Hortic. Sci. 105: 642-644, 1980.

Tombesi S., Lampinen B.D., Metcalf S., DeJong T.M.: Relationships between spur-and orchard-level fruit bearing in almond (Prunus dulcis). - Tree Physiol. 31: 1413-1421, 2011.

Vemmos S.N.: Net photosynthesis, stomatal conductance, chlorophyll content and specific leaf weight of pistachio trees (cv. 'Aegenes') as influenced by fruiting. - J. Hortic. Sci. 69: 775-782, 1994.

Vemmos S.N.: Carbohydrate content of inflorescent buds of defruited and fruiting pistachio (Pistacia vera L.) branches in relation to biennial bearing. - J. Hortic. Sci. Biotech. 74: 94-100, 1999.

Vemmos S.N.: Effects of shoot girdling on bud abscission, carbohydrate and nutrient concentrations in pistachio (Pistacia vera L.). - J. Hortic. Sci. Biotech. 80: 529-536, 2005.

Vemmos S.N., Pontikis C.A., Tolia-Marioli A.P.: Respiration rate and ethylene production in inflorescence buds of pistachio in relation to alternate bearing. - Sci. Hortic. 57: 165-172, 1994.

Vemmos S.N., Papagiannopoulou A., Coward S.: Effects of shoot girdling on photosynthetic capacity, leaf carbohydrate, and bud abscission in pistachio (Pistacia vera L.). Photosynthetica 50: 35-48, 2012.

Wareing P.F.: The Physiology of the Whole Tree: Report E. Malling Research Station for 1967. Pp. 55-68. East Melling Research, East Malling, Kent 1968.

Watson M.A., Casper B.B.: Morphogenetic constraints on patterns of carbon distribution in plants. - Annu. Rev. Ecol. Syst. 15: 233-258, 1984.

Weinbaum S.A., Muraoka T.T.: Nitrogen redistribution from almond foliage and pericarp to the almon embryo. - J. Am. Soc. Hortic. Sci. 111: 224-228, 1986.

Weinbaum S.A.: Foliar nutrition of fruit trees. - In: Neumann P.M. (ed.): Plant Growth and Leaf-Applied Chemicals. Pp. 81100. CRC Press, Inc., Boca Raton 1988.

Weinbaum S.A., Neiderholzer F.J.A., Ponchner S. et al.: Nutrient uptake by cropping and defruited field-grown "French" prune trees. - J. Am. Soc. Hortic. Sci. 119: 925-930, 1994.

Woodall G.S., Dodd I.C., Stewart G.R.: Contrasting leaf development within the genus Syzygium. - J. exp. Bot. 49: 79-87, 1998. 